\title{
SIGNIFICANCE OF BACKGROUND \\ ACTIVITY AND POSITIVE SHARP WAVES IN \\ NEONATAL ELECTROENCEPHALOGRAM AS \\ PROGNOSTIC OF CEREBRAL PALSY
}

\author{
Márcia de Oliveira Nicolini Nosralla', Délrio Façanha Silva², Ricardo Vieira Botelho ${ }^{3}$
}

\begin{abstract}
Objective: To study the significance of electroencephalographic background activity and positive sharp waves in neonatal electroencephalogram as prognostic of cerebral palsy. Method: We studied prospectively and sequentially 73 newborns who had severe neonatal complications (neonatal anoxia, seizures, respiratory distress, sepsis, and meningitis). Nineteen newborns were excluded and 54 children formed the object of our study and were followed for 2 years. We analyzed gestational age, conceptional age, electroencephalographic background activity and positive sharp waves, which were correlated with cerebral palsy. Results: There were no statistically significant correlation between gestational age and conceptional age and cerebral palsy; the electroencephalographic background activity was correlated with cerebral palsy as well as the positive sharp waves. Conclusion: Children with electroencephalographic background activity markedly abnormal and accompanied by positive sharp waves were associated with a worse prognosis.
\end{abstract}

KEY WORDS: neonatal, cerebral palsy, newborn, anoxia, seizures, sepsis, meningitis, children, gestacional age, prognosis.

\section{Valor do ritmo de base e da onda aguda positiva no eletrencefalograma neonatal como prognóstico da paralisia cerebral}

Resumo - Objetivo: Estudar o valor do ritmo de base e das ondas agudas positivas no eletrencefalograma neonatal como prognóstico da paralisia cerebral. Método: Nós estudamos, prospectiva e sequencialmente, 73 recém-nascidos que apresentaram complicações neonatais graves (anoxia neonatal, crises convulsivas, desconforto respiratório, septicemia e meningite). Dezenove recém-nascidos foram excluídos e 54 crianças formaram o objeto do nosso estudo e foram seguidas por 2 anos. Nós analisamos a idade gestacional, a idade corrigida, o ritmo de base e as ondas agudas positivas, que foram correlacionadas com a paralisia cerebral. Resultados: Não houve correlação estatisticamente significante entre as idades gestacional e corrigida com a paralisia cerebral; o ritmo de base foi correlacionado com a paralisia cerebral, tanto quanto as ondas agudas positivas. Conclusão: Crianças com o eletrencefalograma com o ritmo de base marcadamente anormal e ondas agudas positivas estão associadas com pior prognóstico neurológico.

PALAVRAS-CHAVE: neonatal, paralisia cerebral, recém-nascido, anoxia, crises, sepsis, meningite, crianças, idade gestacional, prognóstico.

The mortality and morbidity of high risk neonates, defined as those with severe neonatal complications (neonatal anoxia, seizures, respiratory distress, sepsis, and meningitis), has declined due to advances in obstetrics and neo- natal intensive care unit. However, neurologic sequelae remain a serious public health problem. Consequently, determining neurologic prognosis of children with cerebral lesions remains a key concern for relatives and health pro-

\footnotetext{
Hospital e Maternidade Cruz Azul de São Paulo e Hospital do Servidor Público Estadual “Francisco Morato de Oliveira” - IAMSPE, São Paulo SP, Brazil: ${ }^{1}$ Médica Neurofisiologista do Hospital e Maternidade Cruz Azul de São Paulo; ${ }^{2}$ Neurologista, Unidade de Vídeo-EEG do CITE (Centro de Investigação e Tratamento das Epilepsias) do Hospital Beneficiência Portuguesa; ${ }^{3}$ Doutor em Ciências-Professor do Programa de Pós-graduação em Ciências da Saúde - IAMSPE.
}

Received 6 October 2008, received in final form 19 March 2009. Accepted 18 May 2009.

Dra. Márcia de Oliveira Nicolini Nosralla - Avenida Brigadeiro Luiz Antônio 3333 / 24 -01401-001 São Paulo SP - Brasil. E-mail: cenosralla2@terra.com.br 
fessionals alike. This has led to a number of researchers establishing criteria for determining neurologic prognosis in these neonates ${ }^{1-11}$.

Interest in this subject grew when new concepts regarding the neonatal electroencephalogram (NEEG) were formulated in $1938^{12}$ and stimulated many researchers in the observation of the electroencephalophic background activity (BA) of newborn normal and pathological in different age $\mathrm{e}^{2-3,6-7,9-12}$. The presence of positive sharp waves (PSW) on the central and temporal areas of the NEEG in preterm infants (defined as gestational age less than 37 weeks) with intraventricular haemorrhage was reported for the first time in $1972^{5}$. Further associations of PSW were subsequently described including periventricular leukomalacia, other types of intracranial haemorrhage, hydrocephaly, meningitis, various amino acid deficiency diseases and midline infarcts with electrographic crises, ${ }^{1,913-20}$.

This study was designed to study the significance of $\mathrm{BA}$ and PSW in EEGN as prognostic of cerebral palsy.

\section{METHOD}

This was a prospective sequential study of 73 high risk neonates with a gestational age of between 28 to 42 weeks, who were admitted to the Neonatal Intensive Care Unit of the Hospital and Maternity Cruz Azul in São Paulo, in the period from 2001 to 2005 . Were included in this study, newborns with severe neonatal complications (neonatal anoxia, seizures, respiratory distress, sepsis, and meningitis) and excluding newborns who show genetic syndromes.

The following variables were described for all infants: sex, gestational age (it was determined by calculation from the mother's last menstrual period and the result of the Dubowitz and New Ballard examination for maturity), conceptional age (the gestational age plus the chronological age from birth), Apgar score at one and five minute, birth weight, neonatal comorbidities and maternal complications.

All newborns held the first month of life, neuroimaging study, mainly of cranial ultrasound scan and when necessary, cranial computed tomographic.

The NEEG was done in the first week of life and was recorded at the patient's bedside with 20 channel Neurotec NEUROMAP EQSA 240 electroencephalograph, through the digital method. Twelve surface disc electrodes were applied to the scalp with electrode paste according to the International System 10-20 modified for newborns and recorded with a the technique previously described ${ }^{21-23}$. The set up used in our service was in-line with internationally accepted standards ${ }^{21-22,24}$. Fourteen channels were devoted to NEEG and four recorded polygraphic parameters including electro-oculogram (EOG), electromyogram (EMG), electrocardiogram (ECG) and chest respirations: F3-C3, C3-O1, F3-T3, T3-O1, F4-C4, C4-O2, F4-T4, T4-O2, C3-Cz, $\mathrm{Cz}-\mathrm{C} 4, \mathrm{~T} 3-\mathrm{Cz}, \mathrm{Cz}-\mathrm{T} 4, \mathrm{~T} 3-\mathrm{C} 3, \mathrm{~T} 4-\mathrm{C} 4, \mathrm{EOG}, \mathrm{EMG}, \mathrm{ECG}$ and respiration. Tracing were typically recorded for 60 minutes.
The criteria for analysis applied were those established in the literature ${ }^{8,11,15,21,23-25}$ :

A - The BA was classified into three groups: (0) normal; (1) mildly altered; (2) markedly abnormal.

The records were considered normal if: (1) temporal organization discontinuous NEEG with attenuated periods lasting up to 3 minutes in preterm; (2) the number of delta-brushes decrease with increasing gestational age and conceptional age delta-brush is a rhythmic activity with slow waves, characterized by outbreaks of 8 to 20 cycles / second, 25 to 200 microvoltz in duration from 0.8 to 1.5 cycles / second, with overlapping waves of fast, with a range from 10 to 100 microvoltz; (3) the percentage of interhemispheric synchrony increases with gestational age and conceptional age; (4) the presence of frontal wave acute transitional and frontal rhythmic delta activity in the fullterm (gestational age greater or equal to 37 weeks); (5) sharp transients in all states and all location in the preterm; (6) continuous activity in wakefulness and active sleep and intermittent activity in portions of quiet sleep in fullterm

The records were considered mildly altered when: (1) interhemispheric synchrony less than $25 \%$; (2) poor correlation between clinical parameters and NEEG according to the stage of sleep-wake cycle; (3) mild focal abnormality (excessive sharp wave temporal and / or central, focal attenuation); (4) immaturity for conceptional age - these patterns are specific to children with corrected age less than 2 weeks (Fig 1); (5) low voltage with BA normal; (6) asymmetry $<50 \%$.

It was markedly abnormal when shown: (1) excessive discontinuity for gestational age (the attenuated period exceeds $60 \mathrm{sec}-$ onds); (2) excessive asynchronous for age (asynchronous persistent, more than $25 \%$ in children older than 30 weeks conceptional age); (3) excessively low voltage (below 20 microvoltz) without the characteristic patterns for gestational age; (4) interhemispheric asymmetry more than 50\%; (5) absence of differentiation between sleep stages; (6) excessively slow cerebral electrical activity, without the presence of characteristic patterns for the conceptional age, which persisted in all stages and are not reactive to stimuli (Fig 2); (7) the presence of focal or multifocal discharges (Fig 2); (8) electrographic seizures with or without clinical seizures (Fig 3B); (9) burst-suppression pattern (Fig 3A); (10) inactive.

$B$ - The PSW were classified into two groups: (0) absence of PSW; (1) presence of PSW.

PSW were defined as sharp transient with a duration longer than $400 \mathrm{msec}$, clearly distinguishable from the BA, maximally expressed in the mid-temporal areas (central or temporal), with an initial and predominant surface positive polarity ${ }^{23}$ and with a frequency of greater than 1 per minute ${ }^{15}$. These PSW appear on the second day after birth and steadily increase over subsequent days and weeks, reaching a peak between the second and fourth weeks after birth (mean of 20 days). Generally, they disappear from the registers at 3-4 weeks of age ${ }^{24}$. In full term, the PSW were located in the temporal region. PSW central were most common in preterm. 


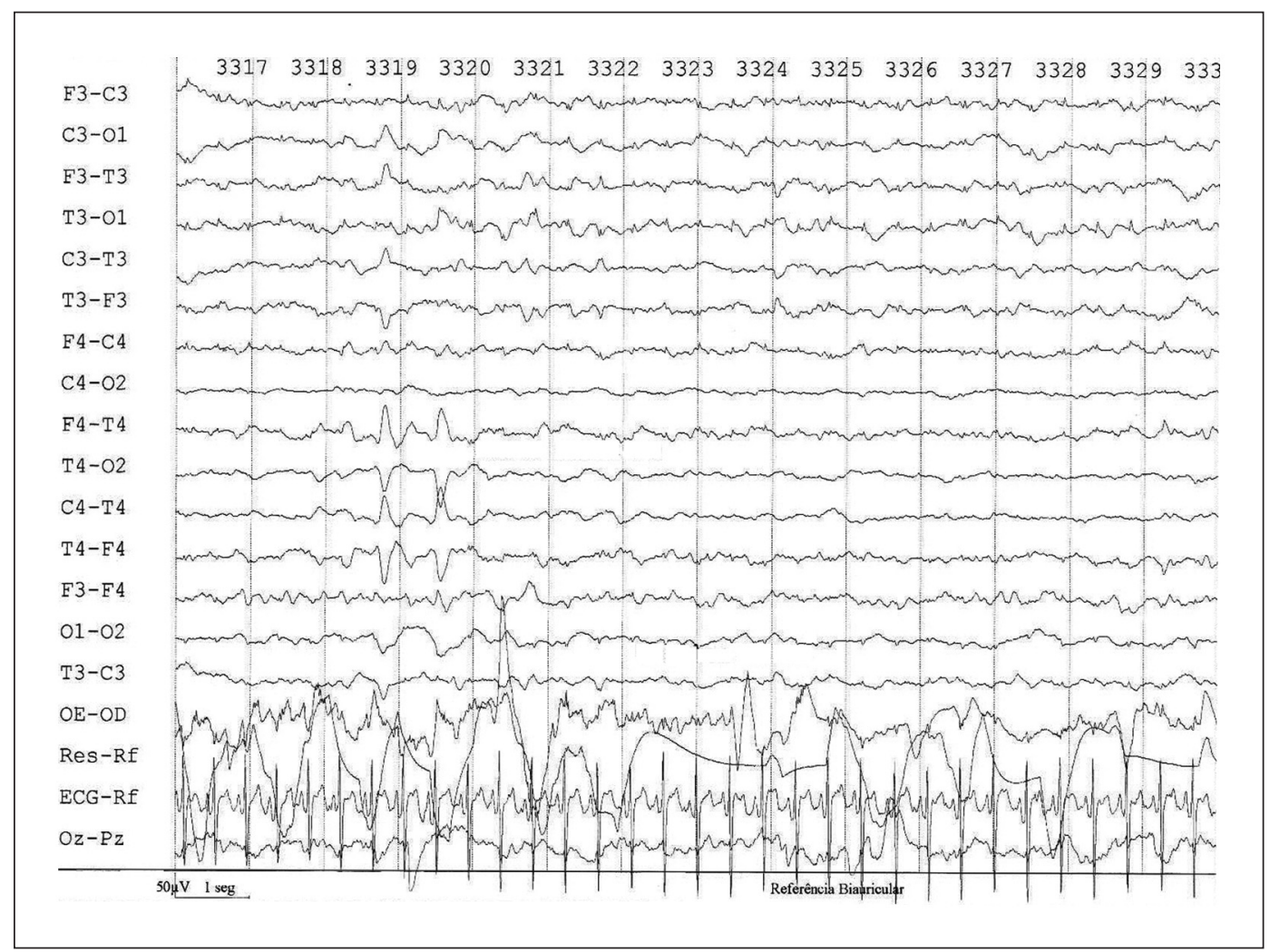

Fig 1. Newborn to $394 / 7$ weeks gestational age and 40 weeks of conceptional age. Presented a EEGN with a BA with immature pattern corrected for age and PSW temporal. Evolved with a left hemiparesis.

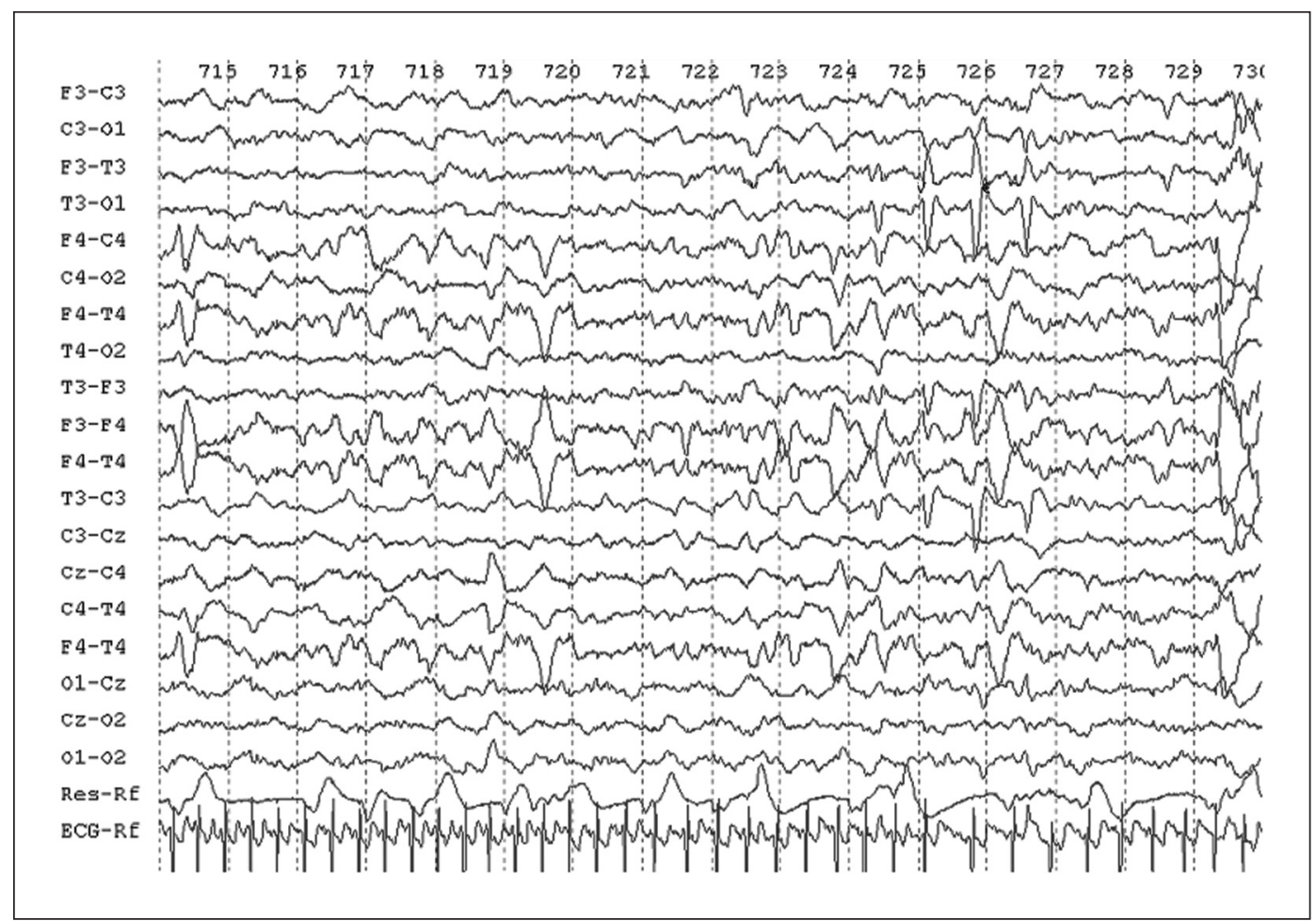

Fig 2. Preterm with gestational age of $302 / 7$ weeks and conceptional age of 31 weeks. Showed a diffuse slowing EEGN with the BA and PSW temporal and central, as well as paroxysmal discharges in the frontal right. Developed with global hypotonia. 
A

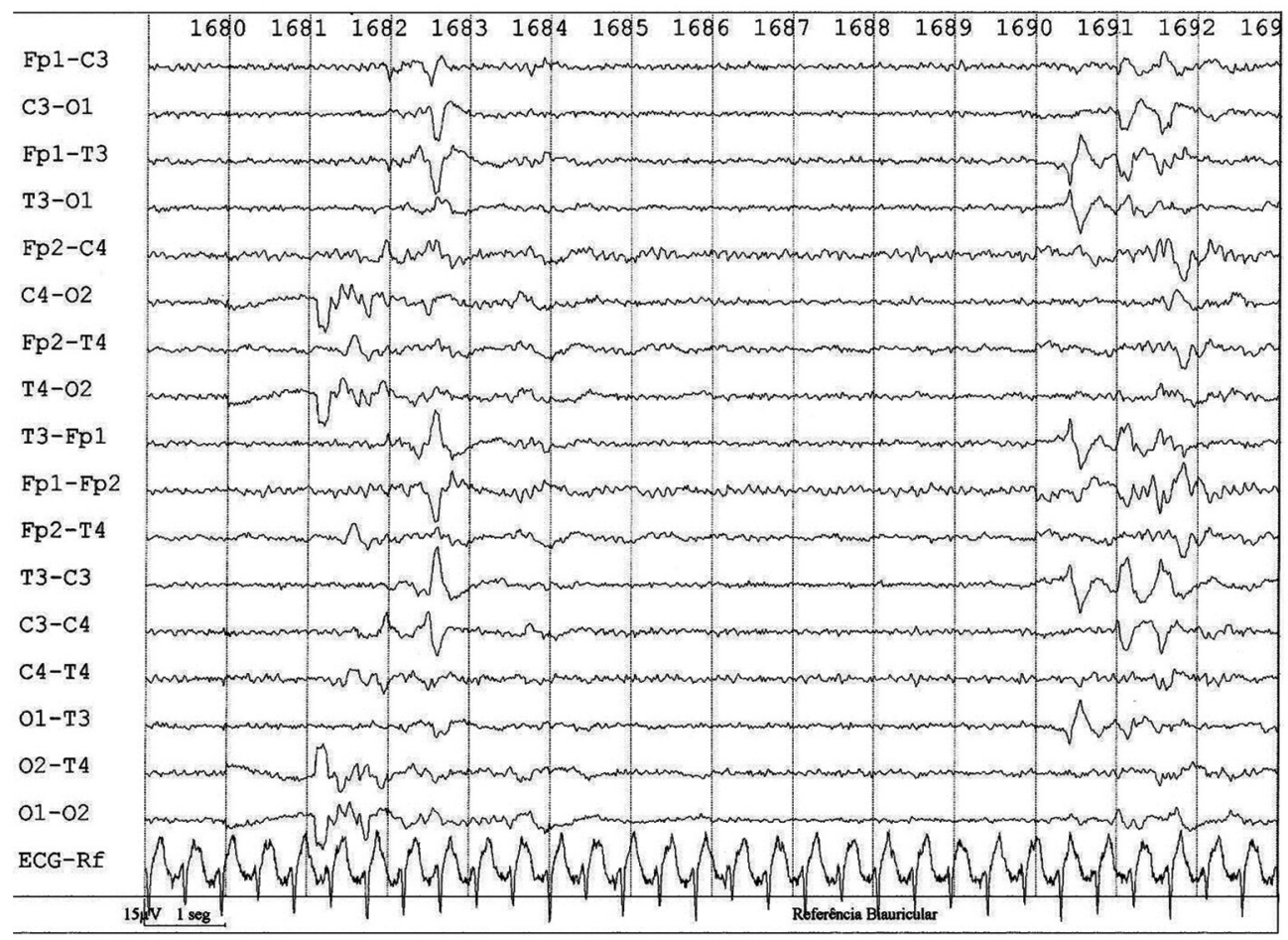

B

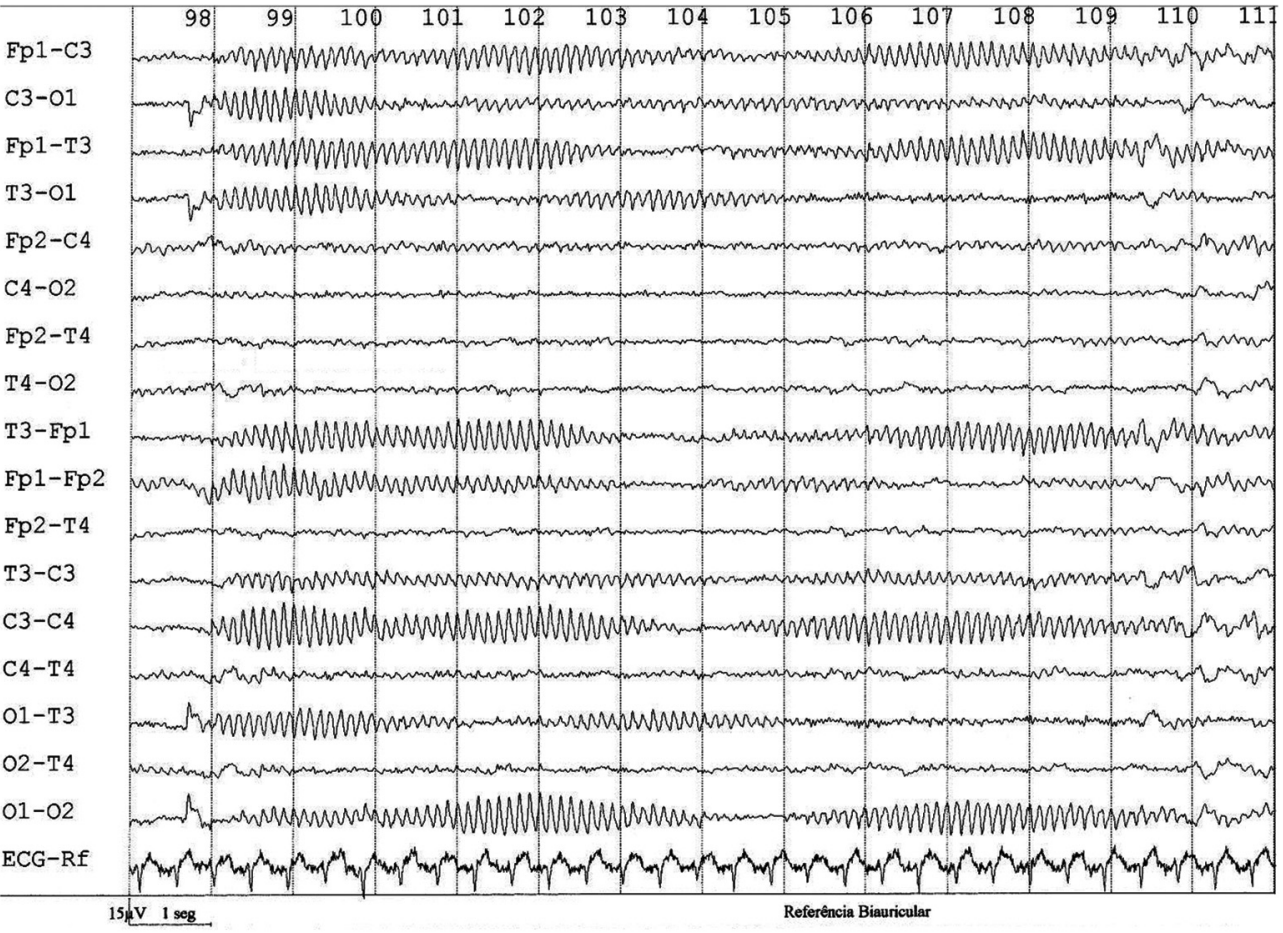

Fig 3. Preterm to $321 / 7$ weeks gestational age and 33 weeks of conceptional age. Presented a EEGN with burst -suppression pattern, PSW left central, left temporal, left frontal and electrographic seizures. [A] Burst-suppression pattern, PSW left central, left temporal, left frontal; [B] Electrographic seizures. 
The newborns included in the study were followed up to two years of age. At the end of this period, were tested in relation to the proportions existing in two age groups, one younger and one older, divided by their median, were classified according to the standard neurological exam ${ }^{26}$ like normal (without cerebral palsy) and abnormal (with cerebral palsy) and then were determined the proportions of variables: occurrence of cerebral palsy, change of BA and the presence of PSW.

At the end of the study, we correlatede the variables gestational age, conceptional age, BA and PSW with cerebral palsy ${ }^{25}$.

\section{Statistical analysis}

The gestational age and conceptional age were described by mean, standard deviation, median and the distribution differences were estimated by non-parametric tests (Mann-Whitney). The correlation between cerebral palsy and the other variables (gestational age, conceptional age, BA and PSW) were performed by the Spearman test. The association between these variables were studied by logist regression test, between BA and cerebral palsy and was calculated by Chi Square, and the association between the PSW and cerebral palsy was calculated using the Fischer exact test. The sensitivity, specificity and positive and negative predictive values were determined from cerebral palsy.

The adopted level of significance was $5 \%(\alpha=0.05)$.

This study was authorized after the appreciation of the Commission on Ethics in Research of the Hospital and Maternity Cruz Azul de São Paulo with free and informed consent signed by parents and guardians.

\section{RESULTS}

Among 73 initially selected newborns for study, 3 $(4.11 \%)$ died of clinical complications, mainly septicemia, during the neonatal period. Two subjects (2.74\%) were excluded as they had a genetic syndrome, and 14 (19.18\%) abandoned treatment before study end point of two years of age. The remaining 54 neonates were included in the study.

Of the 54 infants in this study, 31 (57.40\%) were boys and 23 (42.60\%) were girls; 38 (70.37\%) of the neonates were preterm and 16 (29.63\%) were fullterm (defined as gestational age greater than or equal to 37 weeks at birth). Apgar score at one minute ranged from 1 to 9 (mean of $5 \pm 3$ ) and 5 minutes varied from 2 to 10 (mean $7 \pm 2$ ). Weight of the preterm ranged from $0.790 \mathrm{~g}$ (mean $1475 \pm 0.64 \mathrm{~g}$ ) and of fullterm from $2850 \mathrm{~g}$ to $3070 \mathrm{~g}$ (mean $2952 \pm 0.10 \mathrm{~g}$ ).

The most common maternal complications in the preterm included urinary tract infections, prolonged labor and placenta previa, while in the fullterm, the most frequent maternal complication was prolonged labor. In the neonatal period, the most common complications were respiratory distress, anoxia and convulsions.

Of the 54 newborns (100\%) who underwent the neuroimaging study, 38 (70.37\%) were normal and 14 (25.93\%) showed significant changes (intraventricular hemorrhage grade III or IV with or without periventricular leukomalacia).

At the end of the study, the 54 children were divided into two groups according to neurological examination and 29 (53.7\%) had cerebral palsy and 25 (46.3\%) did not develop with cerebral palsy.

The gestational age of 54 newborns ranged from a minimum of 24 and a maximum of 42 weeks ( $X=33.65+4.31$ weeks and a median of 34 weeks).

The group of 29 newborns with cerebral palsy presented with gestational age and mean $\pm 33.83+4.60$ weeks and the group of 25 newborns without cerebral palsy of 33.44+ 4.02 weeks ( $p=0.76$, Mann-Whitney).

The gestational age of 54 cases was divided by its median, of 34 weeks, in two groups, the youngest with 26 cases of gestational age $<34$ weeks and older with 28 cases $\geq 34$ weeks. Then, the proportions were tested according with occurrence of cerebral palsy, changes in BA and presence of PSW. When confronted the groups there were no statistically significant differences between the proportions calculated (age group $\times$ cerebral palsy - Fisher: $\mathrm{p}=0.78$; age groups $\times \mathrm{BA}-\chi^{2}=0.28: \mathrm{p}=0.86$; Age groups $\times$ PSW - Fisher: $\mathrm{p}=0.39$ ).

Conceptional age followed the gestational age, with slightly higher values. A total of 54 newborns had the minimum 25 and maximum of 42 weeks ( $X=34.30+4.15$ weeks and a median of 34 weeks).

The group of 29 babies born with cerebral palsy had conceptional age of $34.48+4.43$ weeks and the group of 25 newborns without cerebral palsy of $34.08+3.88$ weeks ( $p=0.70$, Mann-Whitney).

Of the 25 newborns (100\%) that progressed with the normal neurological examination at 2 years of age, 19 (76\%) had the BA normal. Of the 29 children (100\%) who had cerebral palsy to 2 years of age, 20 (69\%) showed the BA markedly abnormal in NEEG (Table 1).

There were no difference in proportions between the three groups of BA in the two groups, with and without cerebral palsy $\left(\chi^{2}=20.69, p=0.00003^{*}\right)$.

The PSW group was associated with significantly different with the presence of cerebral palsy (Fisher: $p=0.00963$ ) (Table 2).

Table 1. Distribution of the 54 newborns in the 3 groups do background activity ( $0=$ normal; $1=$ mildly altered; $2=$ markedly abnormal), according to the absent or presence of cerebral palsy.

\begin{tabular}{cccc}
\hline & \multicolumn{2}{c}{ Cerebral palsy } & \\
\cline { 2 - 3 } Background activity & No & Yes & Total \\
\hline 0 & $19(76 \%)$ & $5(17.2 \%)$ & 24 \\
1 & $3(12 \%)$ & $4(13.8 \%)$ & 7 \\
2 & $3(12 \%)$ & $20(69.0 \%)$ & 23 \\
Total & 25 & 29 & 54 \\
\hline
\end{tabular}


Table 2. Distribution of the 54 newborns in the 2 groups of positive sharp waves $(0=a b s e n t$ of positive sharp wave; $1=$ presence of positive sharp waves), according to the absent or presence of cerebral palsy.

\begin{tabular}{cccc}
\hline & \multicolumn{2}{c}{ Cerebral palsy } & \\
\cline { 2 - 3 } Positive sharp waves & No & Yes & Total \\
\hline 0 & $21(84 \%)$ & $14(48.3 \%)$ & 35 \\
1 & $4(16 \%)$ & $15(51.7 \%)$ & 19 \\
Total & 25 & 29 & 54 \\
\hline
\end{tabular}

The BA markedly abnormal and the presence of the PSW were significantly correlated with cerebral palsy (Spearman, $p=0.000001$ and $p=0.0054$ respectively). Gestational age and conceptional age were not correlated (Spearman, $p=0.76$ and $p=0.71$, respectively).

Performed logistic regression with cerebral palsy as a dependent variable, there were significant correlations between cerebral palsy and BA PSW $(R=0.66$ and $R=0.40$, respectively).

\section{DISCUSSION}

Both the families of patients and the medical profession and society eager for prognostic factors to guide the development likely neuropsychomotor of newborns at high risk, ie those with severe neonatal complications (neonatal anoxia, seizures, respiratory distress, sepsis, and meningitis).

According to the literature, examination of the image, the EEGN, the gestational age and conceptional age are the methods used to predict the neurological prognosis of newborns".

The types and location of brain injury in newborns, especially in response to hypoxia-ischemia are related to the time of appearance of the lesion and the nature of the insult ${ }^{23}$. In the fullterm, the main pathology of hypoxia-ischemia is the lesion of the gray matter and the substrate is the pathological lesion of the gray matter. In preterm, the two main consequences of hypoxic-ischemic injury are haemorrhage of germinal matrix and periventricular leukomalacia ${ }^{23}$.

In the neurological development of children, there is spastic diplegia due to damage of pyramidal fibers in the cortex, which passes through the central white substance, or spastic quadriplegia, when the area involved is larger ${ }^{27-29}$. Observed in our patients structural lesions, particularly intraventricular haemorrhage grades III or IV with or without periventricular leukomalacia in $25.93 \%$ of cases, which is similar to published data.

Data from EEGN are designed to bring prognostic information. The BA altered and the presence of PSW is the changes disclosed to EEGN potential correlation with prognosis.
There is evidence suggesting that the BA, showing its maturity by agreeing to gestational age, indicating a good prognosis for normal neurological development. Moreover, when the EEGN presents a BA abnormal, indicates a poor prognosis for children with 1 to 2 years of age, with the possibility of developing cerebral palsy $2,14,18,20,23,29$.

Our study confirmed these data. We observed a predominance of BA normal in the group without cerebral palsy and BA markedly abnormal in patients with cerebral palsy. The disorganization BA was significantly correlated with the presence of cerebral palsy.

The PSW central and PSW temporal are morphologically similar and both are associated with structural brain injury, including intraventricular haemorrhage and periventricular leukomalacia, and other types of intracranial haemorrhage, hydrocephalus, meningitis, and some aminoacidopatias infarction of the middle line with electrographic seizures ${ }^{1,9,13-20,23}$. In the fullterm, the PSW is located in the temporal region.

The PSW seen in children showed the morphological characteristics described above. The PSW were considered pathological by its association with high incidence of abnormalities of BA, both in preterm, newborn and in the end, which were exposed to attacks the central nervous system. Moreover, were associated with structural lesions, mainly intraventricular haemorrhage grades III and IV.

A relevant question in the study of EEGN refers to the different presentations of the routing related to the age of the newborn, because there could be changes in presentation. Separate the group of newborns with and without cerebral palsy checking whether the gestational age and conceptional age were confounding factors in the work. There was no difference in distribution between the ages of the groups with and without cerebral palsy $(x=33.83+4.60 \times X$ weeks $=33.44+4.02$ weeks, Mann-Whitney, $p=0.76)$. The conceptional ages were not different between groups $(x=34.48+4.43 \times$ weeks $=34.08+3.88$ weeks, Mann-Whitney, $\mathrm{p}=0.70$ ).

We conclude that the presence of the BA changed and PSW in EEGN were significantly associated with cerebral palsy in infants at high risk, and the change of BA were more strongly associated with prognosis. Prematurity was not isolated factor related to neurological prognosis.

ACKNOWLEDGMENTS - The authors would like to thank Dr. Roberto Flores Guevara for his help in the discussion of the manuscript ( Université Pierre et Marie Curie - Paris, France) and Dr. Arnaldo Zanoti, of Faculadade of Medicina da Universidade de São Paulo, Brazil.

\section{REFERENCES}

1. Banker BG, Larroche J. Periventricular leukomalacia of infancy, a form of neonatal anoxic encephalopathy. Arch Neurol 1962;7:386-410. 
2. Torres F, Anderson C. The normal E.E.G. of human newborn. Clin Neurophysiol 1985;2:89-103.

3. Biagioni E, Bartelena L, Boldini A, et al. Background EEG activity in preterm infants: correlation of outcome with selected maturational feature. Electroencephalogr Clin Neurophysiol 1994;91:154-161.

4. Blume WT, Dreyfus-Brisac, C. Positive rolandic sharp wave in neonatal EEG: type and significance. Electroencephalogr Clin Neurophysiol 1982;53:277-282.

5. Cukier F, André M, Monod N, Dreyfus-Brisac C. Apport de le EEG au diagnostic des hémorragies intra-ventriculaires du prématuré. Rev EEG Neurophysioll Clin 1972;2:318-322.

6. Lamblin MD, Andre M, Auzoux M, et al. Indications of electroencephalogram in the newborn. Arch Pediatr 2004;11:829-833.

7. Lombroso CT. Neonatal EEG polygraphy in normal and abnormal newborns. In: Niedermeyer E, Lopes da Silva F (Eds). Electroencephalography. $3^{\text {rd }}$ Edition. Baltimore: Urban and Schwarzenberg, 1993:803-875.

8. Murat I. Intérêt discriminatif des pointes positives rolandiques. Contribution au diagnostic des hémorragies intraventriculaires. Thesis for the Doctor of Medicine, Academy of Paris, University René Descartes, Faculty of Medicine Cochin Port Royal, Paris, 1978.

9. Scher MS. Midline electrographic abnormalities and cerebral lesions in the newborn brain. J Clin Neurol 1988;3:135-146.

10. Tharp BR. Neonatal and pediatric electroencephalography. In: Aminoff MJ (Ed). Electrodiagnosis in clinical neurology. Edinburgh: ChurchillLivingstone, 1980:67-117.

11. Tharp BR, Cukier F, Monod N. The prognostic value of the electroencephalogram in premature infants. Electroencephalogr Clin Neurophysiol 1981;51:219-236.

12. Smith JR. The electroencephalogram during normal infancy and childhood. In Rhythmic activities present in the neonate and their subsequent development. J Genet Psychol 1938;53:431-453.

13. Bejar R, Coen RW, Merritt TA, Vaucher Y, Trice J, Centeno RGF. Focal necrose of white matter (periventricular leukomalacia): sonographic, pathologic and electroencephalographic features. AJNR Am J Neuroradiol 1986;60:1073-1079.

14. Marret, S, Parain, D, Samson-Dollfus, D. Positive rolandic sharp waves and periventricular leukomalacia in the newborn. Neuropediatrics 1986;17:199-202.

15. Novotny EJ, Tharp BR, Coen RW, Bejar R, Enzmann D, Vaucher YE. Posi- tive rolandic sharp waves in the EEG of the premature infant. Neurology 1987;37:1481-1486.

16. Okumura A, Hayakawa F, Kato T, Kuno K, Watanabe K. Positive rolandic sharp waves in preterm infants with periventricular leukomalacia: their relation to background electroencephalographic abnormalities. Neuropediatrics 1999;30:278-282.

17. Okumura A, Hayakawa F, Maruyama K, et al. Abnormal sharp transients on electroencephalograms in preterm infants with periventricular leukomalacia. J Pediatr 2003;143:26-30.

18. Clancy RR, Tharp BR. Positive rolandic sharp waves in the electroencephalograms of premature neonates with intraventricular hemorrhage. Electroencephalogr Clin Neurophysiol 1984;57:395-404.

19. Clancy RR, Tharp BR, Enzman D. EEG in premature infants with intraventricular hemorrhage. Neurology 1984;34:583-590.

20. Biagioni E, Bartalena L, Boldrini A, Pieri R, Cioni G. Electroencephalography in infants with periventricular leukomalacia: prognostic featurest at preterm and term age. J Child Neurol 2000;15:1-6.

21. Werner S, Stockard J, Bickford R. Atlas of neonatal electroencephalography. New York: Raven Press, 1977.

22. American EEG Society. Guidelines in EEG and evoked potentials. J Clin Neurophysiol 1986;3(Suppl):S1-S37.

23. Chung HJ, Clancy RR. Significance of positive temporal sharp waves in the neonatal electroencephalogram. Electroencephalogr Clin Neurophysiol 1991;79:256-263.

24. Nunes ML, Costa JC. Manual de EEG e polissonografia neonatal Atlas e traçados. Porto Alegre: EDIPUCRS, 2003.

25. Marret S, Parain D, Jeannot E, Eurin D, Fessard C. Positive rolandandic sharp waves in the EEG of the premature newborn: a five year prospective study. Arch Dis Child 1992;67:948-951.

26. Diament A, Cypel S. Neurologia infantil. $2^{\text {a }}$ Ed. São Paulo: Livraria Atheneu, 1989.

27. Volpe JJ. Intraventricular hemorrhage in the premature infant. Current concepts. Part II. Ann Neurol 1989;25:109-116.

28. Van Bor M, Van Dijk G, Van Belf, Brouwer OF, Van Sweden B. Electrical brain activity in preterm infants at risk for intracranial hemorrhage. Acta Paediatr 1994;83:588-595.

29. Hann JS, Monyer H, Tharp BR. Interburst interval measurements in the EEGs of premature infants with normal neurological outcome. Electroencephalogr Clin Neurophysiol 1989;73:410-418. 